\title{
Protective Influences on the Negative Consequences of Drinking Among Youth
}

Karen A. Randolph

Florida State University College of Social Work

David Russell

Rutgers University Institute for Health, Health Care Policy, and Aging

Research

Kathryn Harker Tillman

Florida State University

Frank D. Fincham

Florida State University College of Human Sciences

The prevention of underage drinking and related outcomes focuses on strengthening protective factors. Using data from the National Longitudinal Study of Adolescent Health $(N=3,862)$, the authors examine the effects of protective factors from three domains of adolescents' lives (individual, familial, and extrafamilial) on experiencing negative consequences of alcohol use, while controlling for relevant risk factors, among youth who have already started drinking. Results showed that protective factors had relatively little influence on not experiencing negative alcohol-related consequences, regardless of social context. One individual protective factor, strategic decision making, was related to negative drinking outcomes in cross-sectional models. In longitudinal models, maternal attachment reduced the likelihood of experiencing negative outcomes over time. The effects of the risk factors remained strong in all models. Findings suggest "mixed-methods" preventive approaches, attending to risk factors, and including strategies to strengthen protective factors across multiple domains of adolescents' lives when striving to affect negative drinking-related outcomes.

Keywords: adolescents; alcohol; prevention

A lcohol use among adolescents in the United States has decreased over the past decade. The percentage of high school students who report ever having consumed alcohol dropped from $81 \%$ in 1999 to $74.3 \%$ in 2005. Regular alcohol use among teens also dropped between 1999 and 
2005, with 7\% fewer youth reporting that they consumed alcohol in the past 30 days (U. S. Centers for Disease Control and Prevention, 2006). More recent data also reflect declines in alcohol consumption among youth (Johnston, O’Malley, Bachman, \& Schulenberg, 2008).

Although the trends are encouraging, underage drinking and the negative consequences associated with it remain a serious public health concern because some youth who drink engage in intensive drinking. National data show that $10 \%$ of 8 th graders, $22 \%$ of 10 th graders, and $26 \%$ of 12 th graders had participated in "binge drinking" (five or more standard drinks per occasion; Johnston et al., 2008). In fact, underage drinkers are likely to consume more alcohol per occasion than adults (Bonnie \& O'Connell, 2004). Binge drinking increases the likelihood of experiencing a variety of negative consequences including decreased school performance, increased likelihood of sexual activity, and even damage to cognitive development (National Center on Addiction and Substance Abuse, 2003).

Prevention has become important in addressing underage drinking. Efforts are directed at identifying factors that protect youth from engaging in drinking and developing strategies to strengthen these protective factors in preventive interventions. Although a number of protective factors have been identified (e.g., Hawkins, Catalano, \& Miller, 1992), less is known about the nature of their relationships with the negative consequences of using alcohol, especially among younger youth who have limited drinking experiences.

In general, research on the consequences of underage drinking examines negative outcomes stemming from acute or chronic drinking (e.g., Bonnie $\&$ O'Connell, 2004). These negative outcomes may occur as a result of a single episode of drinking (e.g., accidental injury or death) or represent long-term effects (e.g., poor school functioning). What have not been as widely studied are the negative consequences that are more proximal to the drinking event (e.g., getting into an argument with a peer or engaging in sexual activity while drinking). In fact, in some cases, it may be these outcomes, rather than the drinking itself, that can lead to serious problems for youth who drink.

Knowledge about the impact of protective factors on experiencing negative drinking-related outcomes can inform prevention efforts, especially for younger youth whose cognitive capacity for abstraction is not fully developed. These youth may have difficulty conceptualizing that they are at risk of suffering the consequences of acute or chronic alcohol use. On the other hand, understanding the link between drinking and proximal negative consequences may be more congruent with the developmental abilities of 
these youth and thus strengthen their motivation to abstain or delay alcohol involvement. We investigate the relative influence of individual, familial, and extrafamilial protective factors on experiencing negative outcomes that are proximal to the drinking event both concurrently and over time.

\section{A Framework of Protection During Adolescence}

Protective factors (i.e., resources that promote positive outcomes) can have a profound influence on averting youth from problem behavior. Much evidence to support the beneficial effects of protective factors comes from the field of developmental psychopathology, in which inquiries focus on resilience, or how youth experience positive adaptation despite adversity (Luthar, 2006). Studies within this discipline examine the underlying mechanisms by which protective factors operate to affect youth outcomes, in the context of exposure to risk. Although this conceptualization is common throughout the literature on protective factors, scholars from other disciplines view risk and protection as opposite ends of a continuum (FelixOrtiz \& Newcomb, 1992), such that an influence becomes a risk factor at the point at which it is negative and a protective factor at the point at which it is positive. Resolving these conceptual differences is beyond the scope of this study. Instead, because our data come from youth who have already started drinking, we use the former view to guide the framework of our analysis and examine protection in the context of risk. We define the variables in this study as either risk or protective factors based on a consensus of previous research and use this framework to investigate three areas of inquiry-the relative influences of protective factors from multiple social environments, the longitudinal impact of protective factors on youth outcomes, and the methods (direct vs. indirect) through which protective factors may affect negative drinking-related outcomes.

Werner and Smith (1982) proposed a system for classifying protective factors. In their prospective study of babies born in Hawaii in 1955, participants and their families were followed into the child's adulthood to determine the protective factors that promoted resilience among the higher risk children. Three clusters of protective factors were found to shape positive outcomes for the at-risk youth, including (a) individual dispositional attributes, (b) family support, and (c) extrafamilial support. This classification system has been widely adopted among child development scientists. We use this system to organize our examination of the impact of protective factors from multiple domains on the outcome of interest. 
A second focus is to explore the dynamic nature of the influence of protective factors on negative drinking-related outcomes in the context of adolescent development. Scholars posit that the influence of some risk and protective factors waxes and wanes across the life cycle in that their presence is more relevant during certain developmental stages than during others (Bronfenbrenner, 1989). This is particularly important during adolescence when developmental changes are dramatic, characterized by rapid changes in physical, psychosocial, and cognitive domains. In this study, we examine relationships between protective factors and negative alcoholrelated outcomes across a span of approximately 2 years.

Finally, protective factors may also influence youth outcomes indirectly by acting as mediators in the link between risk factors and the negative outcomes (Rutter, 1987). As Dearing and Hamilton (2006) explained,

Variables that are more distal to developmental functioning exert their influence via mediators that are more proximal. By analyzing mediators, developmental researchers seek to understand the mechanisms that directly influence development and the chain of events through which those mechanisms exert their influence. (p. 88)

Following in this tradition, we test the mediating role of protective factors in the relationship between risk factors and negative alcohol-related outcomes.

\section{Protective Factors From Multiple Domains and Their Influence on Underage Drinking}

Several individual, familial, and extrafamilial protective factors are associated with reducing underage drinking. At the individual level, factors such as having a positive orientation, feelings of high self-worth, or good decision-making skills help protect youth from engaging in drinking (Scheier, Botvin, \& Baker, 1997; Zweig, Phillips, \& Lindberg, 2002). These factors promote a sense of confidence that can have direct and long-term positive effects on reducing alcohol use (Epstein, Griffin, \& Botvin, 2000).

Of particular interest for preventing underage drinking is the impact of decision-making skills. Adolescence is characterized by increased risk taking as a consequence of the imbalance of factors such as increased sensation seeking and an underdeveloped self-regulatory process (Steinberg, 
2006). This imbalance is a powerful predictor of engaging in risky behaviors such as underage drinking (Donohew et al., 2000). In these instances, decision making is characterized as impulsive rather than strategic and methodical. However, decision making is one of many skills that are malleable and likely targets in prevention efforts (Botvin, 2000). Research has shown that using sound decision-making skills as learned in antialcohol programs reduces the odds of both current and future drinking and can moderate the relationship between risk factors and current use (Epstein, Zhou, Bang, \& Botvin, 2007), but it has no impact on relationships between current risk factors and future use. We speculate that sound decisionmaking skills might also reduce the odds of engaging in the kinds of behaviors that lead to negative drinking-related consequences among youth who drink. As such, we include in both cross-sectional and longitudinal models a measure of strategic decision making to examine its protective influence on negative drinking-related outcomes.

The family also plays an important protective role in diverting youth from underage drinking, although underlying mechanisms remain unclear. Part of this lack of clarity stems from the fact that various parent behaviors have differential effects on youth outcomes. Parental involvement and support provide protection from alcohol and other drug use problems (Best et al., 2005; Crosnoe, Erickson, \& Dornbusch, 2002; Resnick et al., 1997; Zweig et al., 2002), as does parental monitoring and supervision (Latendresse et al., 2008). However, the impact of parent-child attachment is inconclusive. Some studies report no relationship between attachment and youth alcohol use (Eitle, 2005). In other cases, attachment has been found to have an immediate protective impact on underage drinking (Bjarnason, Thorlindsson, Sigfusdottir, \& Welch, 2005), but not over time (van der Vorst, Engels, Meeus, Dekovic, \& Vermulst, 2006). Yet another study has found that the positive impact of parental attachment is not immediately apparent, emerging only later in youths' development (Crawford \& Novak, 2002). Thus, research on the relationship between parent-child attachment and underage drinking behavior is mixed and unclear. We seek to examine this issue in the present study by evaluating the direct and mediating influences of parent-child attachment on negative alcohol-related outcomes concurrently and over time.

The literature reports conceptual and empirical distinctions between mother-child and father-child attachment (Barnes \& Farrell, 1992; Dorius, Bahr, Hoffman, \& Harmon, 2004), indicating that it is important to consider these influences separately. Having a healthy relationship with at least one parent can compensate for the impact of difficulties with the other parent 
(Beardslee, 2002), making youth less likely to engage in risky behaviors. Yet, although some research found positive effects of father involvement on youth outcomes (e.g., Black, Dubowitz, \& Starr, 1999), other studies report that father involvement can negatively affect outcomes (Coley, 2001). We use separate measures of mother and father attachment to account for their potential differential effects.

Finally, factors outside of the family have protective influences on underage drinking. School connectedness is negatively related to problem drinking (Resnick et al., 1997). Some also posit that connections to other institutions, such as formal religious organizations, may protect youth (Sinha, Cnaan, \& Gelles, 2006). Connections to other adults, such as teachers and mentors, can provide more proximal positive influences against alcohol abuse and other risky behaviors (Voisin et al., 2005). These factors may have long-term protective effects. For example, Windle, Mun, and Windle (2005) have shown that religious commitment provides a protective influence against the growth of heavy drinking for youth. The long-term benefits of teacher and other adult prosocial relationships are not as well documented. Yet, this is a relevant question for inquiries about youth outcomes and how they unfold over time, given adolescents' quest for independence that tends to manifest in the outward expansion of their social networks. We investigate this in our analysis.

\section{Risk Factors for Underage Drinking}

Although the focus of this study is on the relationship between protective factors and negative alcohol-related outcomes, a study of protection is incomplete without the consideration of risk. We focus on four risk factors - peer alcohol use, the availability of alcohol in the home, and two indicators of drinking behaviors (i.e., drinking frequency and the average amount of alcohol consumed during each drinking episode).

Peer alcohol use is one of the most notorious risk factors for underage drinking. Youth who associate with peers who use alcohol are much more likely to drink themselves (Stice, Myers, \& Brown, 1998). This association is particularly strong when the friendships are close (Urberg, Degirmencioglu, \& Pilgram, 1997). Peers, in fact, may play a more important role than parents in influencing alcohol use (Beal, Ausiello, \& Perrin, 2001). Negative peer influence tends to increase over time as the role of the family decreases (DiShion, Patterson, Stoolmiller, \& Skinner, 1991), and these influences may operate reciprocally, further supporting the 
growth in alcohol use within the peer network (Curran, 2000). On the other hand, peer effects on youth drinking may depend on the nature of the relationship between youth and their parents. For instance, healthy relationships between parents and youth may counteract negative peer influences (Bray, Adams, Getz, \& McQueen, 2003). Results from one longitudinal study suggested that youth whose parents disapproved of their drinking were more likely to reduce their alcohol use over time, even when controlling for peer influences (Ary, Tildesley, Hops, \& Andrews, 1993). Thus, in addition to examining the direct influence of peer alcohol use on negative alcohol-related outcomes, we also evaluate whether parental factors indirectly protect against negative drinking outcomes by mediating the effects of peer alcohol use.

A popular environmental strategy to prevent underage drinking is to limit access to alcohol through age-based restrictions on purchase and strict enforcement of the laws (Dent, Grube, \& Biglan, 2005). These laws may be less consequential to youth who have easy access to alcohol in their own homes. Easy access to alcohol in the home increases the likelihood of both initiation and experimentation with alcohol (Romelsjo \& Branting, 2000). We examine the impact of the availability of alcohol in the home as a risk factor for experiencing the negative consequences of alcohol use.

Other likely risk factors for experiencing negative drinking-related outcomes are the actual drinking behaviors of youth, such as the frequency of drinking and the amount of alcohol consumed during each drinking episode. These drinking behaviors as outcome measures have been widely studied (e.g., Chen, Grube, \& Madden, 1994). However, we were unable to locate studies that examined the impact of drinking behaviors on negative drinking-related outcomes. Nonetheless, we posit that, especially for youth who have already begun drinking, the frequency of drinking and amount consumed during each episode will increase the likelihood of experiencing negative drinking-related outcomes. We include these measures in our analyses.

Previous research using data from the National Longitudinal Study of Adolescent Health (Add Health) has identified several risk and protective factors related to underage drinking (Resnick et al., 1997), and it has described youth who are vulnerable to alcohol use (Zweig et al., 2002) and who experience negative alcohol-related outcomes (Maney, HighamGardill, \& Mahoney, 2002). We extend this research by examining direct and indirect influences of three sets of protective factors on the negative consequences of alcohol use in both cross-sectional and longitudinal models, while controlling for exposure to relevant risk factors. 


\section{Method}

\section{Data}

We use data from the Add Health, a nationally representative study of adolescents in Grades 7 through 12 in the United States in 1995 (Harris et al., 2003). Based on a multistage, stratified, school-based, cluster sampling design, this study was designed to explain the causes of adolescent health and health behavior, primarily focusing on the multiple contexts in which adolescents live (e.g., families, schools, neighborhoods, peer groups). Included in the sample were students from 80 high schools (both public and private) and corresponding feeder junior high/middle schools. Most minority ethnic groups were sampled in proportion to their size within the United States population; however, smaller ethnic groups were oversampled. Add Health involves multiple waves of data collection and several data collection components. We used data from the adolescent in-home interviews during Wave I, conducted in 1994-1995, and follow-up interviews in Wave II, conducted in 1996. The Wave I in-home interviews captured a total of 20,745 respondents, 14,738 of whom were reinterviewed at Wave II.

Analytic weights were used in all analyses to adjust for the sample design. We also corrected for design effects with appropriate survey techniques (Chantala \& Tabor, 1999). The impact of missing observations for the variables in the model is minimal. The highest percentage of missing data $(2.6 \%)$ was for a control variable (presence of an older sibling).

\section{Participants}

The analytic sample included all in-home interview respondents who participated in Wave I and Wave II interviews, had completed in-home questionnaires, and reported alcohol use (i.e., "ever drank more than two to three times in your life" and "drank at least once in the past 12 months") at both waves. This resulted in a sample size of 3,862 youth for this study. Forty-eight percent of the respondents were men and 52\% were women. The mean age was 16.27 years. Most respondents identified themselves as non-Hispanic White (63\%), whereas $15 \%$ identified as Hispanic, $13 \%$ identified as Black, $6 \%$ as Asian, and $3 \%$ as Native American. Alcohol use does not appear to go beyond experimentation for many of these youth. Most respondents (60\%) reported that they used alcohol no more than once a month. 


\section{Measures}

Negative consequences of alcohol use. Alcohol outcomes at both waves were assessed using a composite of nine items (Maney et al., 2002) that measured the frequency of experiencing a variety of troubles as a consequence of drinking. These questions ask about the number of times respondents had problems over the past 12 months in relationships with parents, partners, and friends, and experiences such as fighting, feeling sick, and behaving in ways that were later regretted, as an outcome of drinking. Five response categories were provided ranging from never to five or more times. The Chronbach's alpha for this measure is .76 at Wave I and .78 at Wave II.

Studies of alcohol use and related outcomes among underage drinkers may encounter problems with the normality of the distribution of outcome measures because so few youth have much experience with drinking. Our evaluation of the normality of the distribution for the outcome measures at each time point reveals a normal distribution (skewness $=2.02$ for both waves). Although the kurtosis statistics (8.88 and 8.71 for Waves I and II, respectively) indicate extraordinary heaviness of the tails, this has little impact on regression estimates (Lomax, 1992).

Individual protective factors. In their research on adolescent risk profiles, Zweig and others (2002) used Add Health data to develop several scales to measure psychosocial adjustment. We included three of these scales-Positive Outlook, Self-Worth, and Decision Making - to evaluate the impact of individual protective factors at Wave I on the negative consequences measure at Waves I and II. Positive Outlook is a composite of four items $(\alpha=.72)$ asking respondents to indicate how often during the past week they felt as good as others, hopeful about the future, happy, and that they enjoyed life. Four response categories were offered ranging from never or rarely to most or all of the time. Self-worth was assessed with five questions $(\alpha=.82)$ that asked respondents to indicate their level of agreement with five statements ("You have a lot to be proud of," "You like yourself the way you are," "You feel like you do everything just about right," "You feel socially accepted," and "You feel loved and wanted"). Five response categories were provided ranging from strongly disagree to strongly agree. Decision making is based on responses to four statements $(\alpha=.74)$ about the use of a strategic and methodological approach to decision making. Response categories are identical to those used to assess self-worth. 
Familial protective factors. We created four scales to measure familial protection at Wave I, including mother's availability, attachment to mother, father's availability, and attachment to father. The availability scales include responses to three questions regarding the frequency of the presence of either parent in the morning, after school, and at bedtime. The five response options ranged from never to always. The alpha coefficients for the mother and father availability scales are .73 and .83, respectively. Attachment to mother and father was assessed using scales that included responses to three items- "How close do you feel to your mother/father?" "How much do you think she/he cares about you?" and "Overall, you are satisfied with your relationship with your mother/father." The alpha coefficients are .93 for the mother attachment scale and .98 for the father attachment scale.

Extrafamilial protective factors. Four measures from Wave I were included in the models as extrafamilial protective factors in the models. Two questions asked respondents about their relationships with adults ("How much do you feel that adults care about you?") and teachers ("How much do you feel that teachers care about you?"), with five response options ranging from not at all to very much. We also included scales to assess the impact of prosocial connections to school and to religion. The school connectedness scale, based on the work of Resnick et al. (1997) and Zweig et al. (2002), asked respondents to indicate their level of agreement with three statements: "You feel close to people at your school," "You feel like part of your school," "You are happy to be at your school," with an alpha coefficient of .78. Religiosity was measured by two questions: "How important is religion to you?" and "In the past 12 months, how often did you attend religious services?" The alpha coefficient was .86 .

Risk factors. We also included four measures of risk in the modelsalcohol availability in the home, peer alcohol use, frequency of drinking, and average number of drinks consumed during each drinking episode. Alcohol availability is a dichotomous measure, "Is alcohol easily available in your home?" (yes $=1$, no $=0$ ). Peer drinking was assessed by responses to the question: "Of your three best friends, how many drink alcohol at least once a month?" Four response categories were offered—no friends, one friend, two friends, and three friends. The frequency of drinking was included as a control variable and assessed the number of days respondents drank alcohol during the past year. Six response options were provided and ranged from one to two days per year to daily or almost every day. Finally, the average number of drinks measure is based on a single question that 
asks: "Think of all the times you have had a drink in the past 12 months. How many drinks did you usually have each time?" The range of response values was 1 to 90 drinks.

Demographic factors. In an effort to parcel out the independent influence of protective factors on negative drinking-related outcomes, we control for demographic characteristics that have been shown in previous research to affect drinking behaviors (e.g., Maney et al., 2002). These factors, measured at Wave I, are gender, age, race/ethnicity, immigrant generation, family structure, and parent education. Respondents' gender, age, and race/ethnicity were based on self-reported data. Immigrant generation is determined from children and parents' countries of birth (and citizen status at birth). Three categories were created-first generation immigrant (foreign born respondents), second generation immigrant (U.S. born children of at least one immigrant), and nonimmigrant. The respondents' family structure was measured with five dichotomous variables, including: two biological parents, biological parent and step parent, single mother, single father, and other family type (e.g., other relatives, group home). Parent education was measured in terms of the highest level of education completed by the respondent's mother or father and was divided into one of five categories, including: less than high school education, high school graduate or equivalent (GED), some college, and college graduate or more. An additional category was created to control for missing data on parent education.

\section{Results}

\section{Data Analyses}

Ordinary Least Squares regression procedures were used to conduct analyses using STATA, version 8 (Long \& Freese, 2006). STATA offers the Huber or White robust estimator of variance that adjusts for the biases of the cluster sampling design. To correct for the unequal probability sampling of the clusters, Add Health grand sample weights were included in all estimation procedures (Chantala \& Tabor, 1999).

The outcome variables, negative consequences of drinking at Waves I and II, were regressed on risk factors (availability of alcohol in the home, peer alcohol use, drinking frequency, and average amount of alcohol consumed at each episode) and individual (positive outlook, self-worth, and 
decision making), familial (mother availability, father availability, mother closeness, and father closeness), and extrafamilial (caring adults, caring teachers, school connection, and religious connection) protective factors at Wave I. The Wave I negative drinking-related outcomes measure was also included as an explanatory variable in the longitudinal models. We examined the relative effects of each set of protective factors individually and in combined models. We also attempted to identify potential protective mechanisms by testing path models between risk factors, protective factors, and Wave II negative drinking-related outcomes. Table 1 provides the means, standard deviations, and ranges for each dependent variable and main predictor.

\section{Changes in Negative Alcohol-Related Outcomes}

Are youth who drink progressively more likely to experience negative alcohol-related outcomes over time? As shown in Table 2, experiencing negative outcomes increases only slightly over time. The percentage of youth who had no experiences with negative consequence due to drinking decreased by just $4.5 \%$ between Waves I and II. In addition, for youth who experienced negative alcohol-related outcomes, the increase in the number of incidences was small. At both waves, most youth (between 60\%-65\%) reported experiencing between 1 and 10 negative consequences due to drinking per year, and another sizable minority (around 30\%) reported not experiencing any negative consequences. Yet, a small number of youth seem to develop serious problems as a consequence of their alcohol use over time. At Wave II, 49 youth (more than three times as many as at Wave I) reported that they had at least 21 experiences with alcohol-related negative consequences in only one year.

\section{Multivariate Findings: Cross-Sectional Analyses}

Cross-sectional analyses indicate that three of the risk factors (peer alcohol use, frequency of drinking, and average number of drinks consumed at each episode) have strong positive relationships with negative consequences due to drinking at Wave I (see Model 1 in Table 3). These relationships remain strong as each set of protective factors is added to the model. Moreover, the estimated coefficients barely change, indicating that the significance of the risk factors cannot be explained by the absence of protective factors. One risk factor, availability of alcohol in the home, has no significant effect on negative alcohol-related outcomes. 
Table 1

Descriptive Statistics for Dependent and Main Predictor Variables $(N=3,862)$

\begin{tabular}{|c|c|c|c|c|}
\hline & $M$ & $S D$ & Minimum & Maximum \\
\hline \multicolumn{5}{|l|}{ Dependent variables } \\
\hline Wave I negative consequences & 3.35 & 4.13 & 0 & 36 \\
\hline Wave II negative consequences & 3.88 & 4.65 & 0 & 36 \\
\hline \multicolumn{5}{|l|}{ Risk factors } \\
\hline Alcohol in the home & 0.39 & 0.49 & 0 & 1 \\
\hline Best friend alcohol use & 1.82 & 1.12 & 0 & 3 \\
\hline Drinking frequency & 1.36 & 1.27 & 0 & 5 \\
\hline Average number of drinks/episode & 5.84 & 7.43 & 0 & 90 \\
\hline \multicolumn{5}{|l|}{ Individual protective factors } \\
\hline Positive outlook & 7.76 & 2.67 & 0 & 12 \\
\hline Self-worth & 19.80 & 3.21 & 5 & 25 \\
\hline Decision making & 14.89 & 2.50 & 4 & 20 \\
\hline \multicolumn{5}{|l|}{ Familial protective factors } \\
\hline Mother availability & 11.18 & 3.56 & 0 & 15 \\
\hline Father availability & 7.15 & 5.00 & 0 & 15 \\
\hline Mother attachment & 12.67 & 3.59 & 0 & 15 \\
\hline Father attachment & 9.05 & 6.05 & 0 & 15 \\
\hline \multicolumn{5}{|l|}{ Extrafamilial protective factors } \\
\hline Adults care & 4.28 & 0.825 & 1 & 5 \\
\hline Teachers care & 3.31 & 0.943 & 1 & 5 \\
\hline School connection & 10.89 & 2.69 & 3 & 15 \\
\hline Religious connection & 5.15 & 2.51 & 0 & 8 \\
\hline
\end{tabular}

Table 2

Percentage of Students Who Experienced Alcohol-Related Negative Consequence $(N=3,862)$

\begin{tabular}{|c|c|c|c|c|c|}
\hline \multirow{2}{*}{$\begin{array}{l}\text { Number of Times } \\
\text { Experienced Negative } \\
\text { Consequences } \\
\text { in the Last Year }\end{array}$} & \multicolumn{2}{|c|}{ Wave I } & \multicolumn{2}{|c|}{ Wave II } & \multirow{2}{*}{$\begin{array}{l}\text { Absolute } \\
\text { Difference }\end{array}$} \\
\hline & $N$ & $\%$ & $N$ & $\%$ & \\
\hline 0 & 1,213 & 31.4 & 1,037 & 26.9 & $4.5 \%$ \\
\hline $1-10$ & 2,397 & 62.1 & 2,493 & 64.5 & $2.4 \%$ \\
\hline $11-20$ & 237 & 6.1 & 283 & 7.3 & $1.2 \%$ \\
\hline $21-36$ & 15 & 0.4 & 49 & 1.3 & $0.9 \%$ \\
\hline
\end{tabular}


Table 3

Standardized Regression Coefficients for Wave I Risk and Protective Factor Variables Regressed on Wave I Negative Consequences of Drinking Variable $(N=3,862)$

\begin{tabular}{|c|c|c|c|c|c|}
\hline \multirow[b]{2}{*}{ Variables } & \multicolumn{5}{|c|}{ Models } \\
\hline & 1 & 2 & 3 & 4 & 5 \\
\hline \multicolumn{6}{|l|}{ Risk factors } \\
\hline Alcohol in the home & $n s$ & $n s$ & $n s$ & $n s$ & $n s$ \\
\hline Best friend alcohol use & $.12 * * *$ & $.12 * * *$ & $.12 * * *$ & $.12 * * *$ & $.11 * * *$ \\
\hline Drinking frequency & $.34 * * *$ & $.33 * * *$ & $.34 * * *$ & $.33 * * *$ & $.33^{* * *}$ \\
\hline $\begin{array}{l}\text { Average number of } \\
\text { drinks/episode }\end{array}$ & $.14 * * *$ & $.14 * * *$ & $.14 * * *$ & $.14 * * *$ & $.14 * * *$ \\
\hline \multicolumn{6}{|l|}{ Individual protective factors } \\
\hline Positive outlook & & $n s$ & & & $n s$ \\
\hline Self-worth & & $-.05^{*}$ & & & $n s$ \\
\hline Decision making & & $-.07 *$ & & & $-.06 *$ \\
\hline \multicolumn{6}{|c|}{ Extrafamilial protective factors } \\
\hline Adults care & & & & $n s$ & $n s$ \\
\hline Teachers care & & & & $n s$ & $n s$ \\
\hline School connection & & & & $-.04 *$ & $n s$ \\
\hline Religious connection & & & & $n s$ & $n s$ \\
\hline$R^{2}$ & .247 & .257 & .250 & .253 & .260 \\
\hline
\end{tabular}

Notes: Equations include controls for age, gender, race/ethnicity, immigrant status, family structure, older sibling, and parent education. Relations between familial protective factors and the outcome variable (Model 3) were insignificant and thus not included in the table. ${ }^{*} p<.05$. $* * p<.01 . * * * p<.001$.

The effects of protective factors on the experience of negative drinkingrelated outcomes are not as strong as expected. Models that test the separate impact of individual, familial, and extrafamilial protective factors (Models 2,3 , and 4) show that some individual and extrafamilial variables (selfworth, decision making, and school connection) are significantly associated with negative drinking-related outcomes at Wave I. However, only one individual protective factor, decision making, remains significant in the full model (Model 5).

\section{Multivariate Findings: Longitudinal Analyses}

Results of the longitudinal analyses show that the frequency of drinking at Wave I remained a strong predictor of experiencing negative 
Table 4

Standardized Regression Coefficients for Wave I Risk and Protective Factor Variables Regressed on Wave II Negative Consequences of Drinking Variable $(N=\mathbf{3 , 8 6 2})$

\begin{tabular}{|c|c|c|c|c|c|}
\hline \multirow[b]{2}{*}{ Variables } & \multicolumn{5}{|c|}{ Models } \\
\hline & 1 & 2 & 3 & 4 & 5 \\
\hline \multicolumn{6}{|l|}{ Risk factors } \\
\hline Alcohol in the home & $n s$ & $n s$ & $n s$ & $n s$ & $n s$ \\
\hline Best friend alcohol use & $n s$ & $n s$ & $n s$ & $n s$ & $n s$ \\
\hline Drinking frequency & $.11 * * *$ & $.10 * * *$ & $.10^{* * *}$ & $.10 * * *$ & $.10 * * *$ \\
\hline $\begin{array}{l}\text { Average number of } \\
\text { drinks/episode }\end{array}$ & $n s$ & $n s$ & $n s$ & $n s$ & $n s$ \\
\hline $\begin{array}{l}\text { Wave I negative } \\
\text { consequences }\end{array}$ & $.43 * * *$ & $.43 * * *$ & $.43 * * *$ & $.43 * * *$ & $.43 * * *$ \\
\hline \multicolumn{6}{|l|}{ Familial protective factors } \\
\hline Mother availability & & & $n s$ & & $n s$ \\
\hline Father availability & & & $n s$ & & $n s$ \\
\hline Attachment to mother & & & $-.08 * *$ & & $-.07 *$ \\
\hline Attachment to father & & & $n s$ & & $n s$ \\
\hline$R^{2}$ & .272 & .273 & .276 & .273 & .276 \\
\hline
\end{tabular}

Note: Equations include controls for age, gender, race/ethnicity, immigrant status, family structure, presence of older sibling, and parent education. Relations between individual and extrafamilial protective factors and the outcome variable (Models 2 and 4) were insignificant and thus not included in the table.

$* p<.05$. $* * p<.01 . * * * p<.001$.

alcohol-related outcomes at Wave II across all models (see Table 4). Experiencing negative consequences due to drinking at Wave I is also highly predictive of maintaining this risky set of behaviors later on. When controlling for negative consequences at Wave I, however, peer alcohol use and the average number of drinks consumed at Wave I do not significantly predict negative consequences at Wave II. The impact of protective factors on negative consequences, however, appears to change over time. In contrast to the cross-sectional models, none of the individual or extrafamilial protective factors significantly predicted negative consequences at Wave II.

The absence of an association between Wave I decision making and Wave II negative outcomes may indicate that strategic decision making has an indirect effect on Wave II negative outcomes by reducing the impact of Wave I negative outcomes. To investigate this, we conducted a path analysis 
examining the association between decision making and negative drinking outcomes at Waves I and II. Results (available on request) showed that the protective influence of decision making at Wave I did not attenuate the significant association between Wave I and Wave II negative drinking outcomes. Thus, our findings suggest that the protective influence of decision making on negative drinking outcomes do not extend over time.

Higher levels of maternal attachment at Wave I decrease the likelihood of experiencing negative alcohol-related consequences at Wave II, when familial protective factors were tested alone with risk factors (Model 3) and in the full model (Model 5). This is interesting given that maternal attachment was not associated with the Wave I outcome measure. Perhaps, attachment to one's mother only reduces the exposure to risk factors for experiencing negative alcohol-related outcomes as youth age, as others have found (Crawford \& Novak, 2002). To examine this, we tested path models to determine whether relationships between the Wave I risk factors that were significant in the longitudinal model (i.e., drinking frequency and Wave I negative consequences) and Wave II negative consequences were mediated by Wave I maternal attachment. Findings (available on request) indicated that attachment to mother was associated with reduced drinking frequency $(\beta=-.029, p<.05)$ but did not account for the connection between Wave I risk factors and Wave II negative drinking-related outcomes.

\section{Discussion}

The Add Health is based on the premise that factors across a variety of social contexts affect adolescents' choices for engaging in healthy or unhealthy behaviors. This study examined the relative impact of protective factors in three key social contexts on the likelihood of experiencing negative alcohol-related outcomes among underage drinkers who participated in the Add Health study. The results showed that, among youth who have already started drinking, protective factors had relatively little influence on whether they experienced negative consequences as a result of alcohol use, regardless of social context. In cross-sectional analyses, only one individual-level protective factor, strategic decision making, reduced the risk for negative drinking-related consequences. Longitudinally, only one familiallevel protective factor, maternal attachment, was associated with a lower likelihood of experiencing the negative drinking outcomes. In both crosssectional and longitudinal models, protective factors accounted for almost none of the unique variance in the negative outcome measures. 
We expected that each set of protective factors would have a unique influence on adverse alcohol outcomes, net of risk factors. Instead, findings showed that familial and extrafamilial protective factors were not related to negative drinking-related outcomes at Wave I, and individual and extrafamilial protective factors did not affect the drinking outcomes measure at Wave II. Moreover, similar to previous research (e.g., Pollard, Hawkins, \& Arthur, 1999), the magnitude of the associations between protective factors and negative drinking outcomes that were significant were relatively small compared to those of the risk factors. As these youth had already begun drinking, perhaps they have also begun to establish beliefs and norms that support the behavior and put them at increased risk for experiencing negative alcohol-related outcomes. It may also suggest that, relative to protective factor influences, these youth are more susceptible to the effects of risk factors, which strengthen their beliefs and norms about drinking. Perhaps the primary focus of prevention for youth who have already started drinking should be on interrupting or reducing exposure to factors that increase risk for negative outcomes (e.g., peer alcohol use and drinking frequency).

We also expected that relationships between protective factors and negative drinking outcomes would differ in cross-sectional and longitudinal models. This expectation was partially supported. Only one individual protective factor, strategic decision making, was significant in cross-sectional models. It had no effect, either directly or indirectly, over time. Decision making is an internal process, thereby more proximal to the outcome, relative to familial and extrafamilial factors. Thus, it seems likely that the effects of proximal measures such as strategic decision making would be stronger in the immediate context of experiencing the outcome. With regard to prevention, this suggests some potential benefits in strengthening strategic decision making skills on an ongoing basis.

The significance of strategic decision making in protecting underage drinkers from experiencing negative drinking-related consequences is consistent with previous intervention research (Botvin, 2000). Strategic decision making can counteract adolescents' tendency toward risk taking and sensation seeking by helping them to recognize high-risk situations and then using refusal skills to avoid drinking. However, the finding raises questions about processes by which strategic decision making protects against negative drinking-related outcomes. For instance, are youth with higher levels of strategic decision-making skills less likely to engage in risky behaviors, sensation seeking, and alcohol involvement during adolescence? This is an important area for future research with youth who have already initiated alcohol use. 
One family-level protective factor, maternal attachment, at Wave I proved to be important. Consistent with Crawford and Novak's (2002) research, attachment did not reduce the likelihood of experiencing negative drinking-related outcomes concurrently, but it did predict fewer negative drinking-related outcomes at Wave II. These findings may reflect the tension between separation and attachment during adolescence, most often manifested in relationships with parents. On average, these teens were about 18 years old at Wave II. Perhaps the protective effects of relational familial factors such as maternal attachment (as opposed to monitoring and supervision) do not become evident until the later teen years, when youth resolve their issues of separation and attachment and become more open to engaging in prosocial relationships with their parents (Bray, Adams, Getz, $\&$ Stovall, 2001). Given adolescents' struggles for independence, within the context of the potential benefits of parent-child attachment, parents may need to adapt their parenting skills (and perhaps their beliefs about the level and nature of their involvement with their children) in response to the developmental needs of these youth. Although beyond the scope of this inquiry, these issues are important areas for future research.

Finally, also consistent with previous research (e.g., D'Amico \& McCarthy, 2006), longitudinal analyses revealed that the experience of negative drinking-related consequences at Wave I increases the likelihood of experiencing negative drinking-related consequences at Wave II. Additional analyses examining whether this finding is an artifact of the case outliers (i.e., cases of those youth who experienced a relatively large number of negative drinking-related consequences) showed no differences with the results presented. Apparently, youth who experience a high number of negative drinking-related consequences are not likely to modify the future drinking behaviors in a positive direction. If so, this provides support for prevention approaches that emphasize the potential dangers of alcohol use and related outcomes.

In summary, we found little support for focusing on protective factors alone to prevent youth from experiencing negative alcohol-related outcomes. Given the powerful impact of the risk factors, intervention strategies should address both risk and protective factors. However, the results of our study suggest that the emphasis should be on reducing the impact of risk factors, particularly risks associated with having friends who drink and drinking behaviors. Our findings also underscore the importance of including in intervention strategies protective factors from different social contexts, and it support previous studies that have shown the benefits of long-term intervention approaches and periodic booster sessions (Botvin, 
2000). Thus, interventions should be based on a mixed-methods approach with periodic booster sessions that focuses on (a) reducing the effects of risk factors, while strengthening the effects of protective factors on alcoholrelated outcomes, and (b) strategies that specifically concentrate on protective factors from the social contexts that are relevant. For instance, strategies may include training on strategic decision-making skills to resist peer pressure for short-term protection and family-based efforts to enhance parent-child attachment for long-term protection from negative drinking related experiences.

These findings should be interpreted within the limitations of the study. Although the study builds on existing alcohol prevention research, experiencing negative alcohol-related outcomes is likely to be affected by other protective factors that were not included in the analyses. For instance, parental monitoring has a strong negative impact on alcohol use and binge drinking among youth (e.g., Bahr, Hoffman, \& Yang, 2005). This was not directly measured in the Add Health study. Although we attempted to capture this process by including the parent availability variables, it is likely that the full impact of parental monitoring has not been assessed here. Genetic effects were also not evaluated in this study, although several experts have called for their inclusion in developmental studies (e.g., Luthar, 2006). Emerging research suggests that this may be a promising avenue in understanding variations of alcohol use among youth (e.g., Volkow et al., 2006), and by extension, negative alcohol-related outcomes. Third, we relied on selfreported data to conduct the analyses. Although previous research provides considerable support for the reliability of this approach in measuring alcohol use among youth (e.g., Lintonen, Ahlstrom, \& Metso, 2004), we were unable to locate studies evaluating the reliability of self-reported information on the negative consequences of alcohol use. Nonetheless, the advantages of this study outweigh its limitations. The rigor of the Add Health study design supports fairly definitive conclusions about the findings with a large, nationally representative sample of youth. Both risk and protective factors are important in addressing the negative consequences of underage drinking and, especially for protective factors, their effects are dynamic in that their influence appears to change over time.

\section{References}

Ary, D., Tildesley, E., Hops, H., \& Andrews, J. (1993). The influence of parent, sibling, and peer modeling and attitudes on adolescent use of alcohol. International Journal of the Addictions, 28, 553-880. 
Bahr, S. J., Hoffman, J. P., \& Yang, X. (2005). Parental and peer influences on the risk of adolescent drug use. Journal of Primary Prevention, 26, 529-551.

Barnes, G. M., \& Farrell, M. P. (1992). Parental support and control as predictors of adolescent drinking, delinquency, and related problem behaviors. Journal of Marriage and the Family, 54, 763-776.

Beal, A., Ausiello, J., \& Perrin, J. (2001). Social influences on health-risk behaviors among minority middle school students. Journal of Adolescent Health, 28, 474-480.

Beardslee, W. R. (2002). Out of the darkened room: When a parent is depressed: Protecting the children and strengthening the family. New York: Little, Brown, and Company.

Best, D., Gross, S., Manning, V., Gossop, M., Witton, J., \& Strang, J. (2005). Cannabis use in adolescents: The impact of risk and protective factors and social functioning. Drug and Alcohol Review, 24, 483-488.

Bjarnason, T., Thorlindsson, T., Sigfusdottir, I., \& Welch, D. (2005). Familial and religious influences on adolescent alcohol use: A multi-level study of students and school communities. Social Forces, 84, 375-390.

Black, M., Dubowitz, H., \& Starr, R. (1999). African American fathers in low income, urban families: Development, behavior, and home environment of their three-year old children. Child Development, 70, 967-978.

Bonnie, R. J., \& O'Connell, M. E. (2004). Reducing underage drinking: A collective responsibility. Washington, DC: Institute of Medicine, National Academies Press.

Botvin, G. J. (2000). Preventing drug abuse in schools: Social and competence enhancement approaches targeting individual level etiologic factors. Addictive Behaviors, 25, 887-897.

Bray, J. H., Adams, G. J., Getz, J. G., \& Stovall, T. (2001). Interactive effects of individuation, family factors, and stress on adolescent alcohol use. American Journal of Orthopsychiatry, 71, 436-449.

Bray, J. H., Adams, G. J., Getz, J. G., McQueen, A. (2003). Individuation, peers, and adolescent alcohol use: A latent growth analysis. Journal of Consulting and Clinical Psychology. 71(3), 553-564.

Bronfenbrenner, U. (1989). Ecological systems theory. Annals of Child Development, 6, 187-249.

Chantala, K., \& Tabor, J. (1999). Strategies to perform a design-based analysis using the add health data. Chapel Hill: University of North Carolina at Chapel Hill.

Chen, M.-J., Grube, J. W., \& Madden, P. A. (1994). Alcohol expectancies and adolescent drinking: Differential prediction of frequency, quantity, and intoxication. Addictive Behaviors, 19, 521-529.

Coley, R. (2001). (In)visible men: Emerging research on low-income, unmarried, and minority fathers. American Psychologist, 56, 743-753.

Crawford, L. A., \& Novak, K. B. (2002). Parental and peer influences on adolescent drinking: The relative impact of attachment and opportunity. Journal of Child \& Adolescent Substance Abuse, 12(1), 1-26.

Crosnoe, R., Erickson, K., \& Dornbusch, S. (2002). Protective functions of family relationships and school factors on the deviant behavior of adolescent boys and girls. Youth \& Society, 33, 515-544.

Curran, P. J. (2000). A latent growth curve framework for the study of developmental trajectories in adolescent substance use. In J. S. Rose, L. Chassin, C. C. Presson, \& S. J. Sherman (Eds.), Multivariate applications in substance use research (pp. 1-42). Mahwah, NJ: Lawrence Erlbaum. 
D'Amico, E., \& McCarthy, D. (2006). Escalation and initiation of younger adolescents' substance use: The impact of perceived peer use. Journal of Adolescent Health, 39, 481-487.

Dearing, E., \& Hamilton, L. C. (2006). Contemporary advances and classic advice for analyzing mediating and moderating variables. Monographs of the Society for Research in Child Development, 71(3), 88-104.

Dent, C. W., Grube, J. W., \& Biglan, A. (2005). Community level alcohol availability and enforcement of possession laws as predictors of youth drinking. Preventive Medicine 40, 355-362.

DiShion, T., Patterson, G., Stoolmiller, M., \& Skinner, M. (1991). Family, school, and behavioral antecedents to early adolescent involvement with antisocial peers. Developmental Psychology, 27, 172-180.

Donohew, L., Zimmerman, R., Cupp, P. S., Novak, S., Colon, S., \& Abell, R. (2000). Sensation seeking, impulsive decision-making, and risky sex: Implications for risk-taking and design of interventions. Personality and Individual Differences, 28, 1079-1091.

Dorius, C. J., Bahr, S. J., Hoffman, J. P., \& Harmon, E. L. (2004). Parenting practices as moderators of the relationship between peers and adolescent marijuana use. Journal of Marriage and the Family, 66, 163-178.

Eitle, D. (2005). The moderating effects of peer substance use on the family structureadolescent substance use association: Quantity vs. quality of parenting. Addictive Behaviors, 30, 963-980.

Epstein, J. A., Griffin, K. W., \& Botvin, G. J. (2000). Role of general and specific competence skills in alcohol use among inner-city adolescents. Journal of Studies on Alcohol, 61, 379-386.

Epstein, J., Zhou, X., Bang, H., \& Botvin, G. (2007). Do competence skills moderate the impact of social influences to drink and perceived social benefits of drinking on alcohol use among inner-city adolescents? Prevention Science, 8, 65-73.

Felix-Ortiz, M., \& Newcomb, M. D. (1992). Risk and protective factors for drug use among Latino and white adolescents. Hispanic Journal of Behavioral Sciences, 14, 291-309.

Harris, K. M, Florey, F., Tabor, J. W., Bearman, P. S., Jones, J., \& Udry, J. R. (2003). The national longitudinal study of adolescent health: Study design. Chapel Hill: University of North Carolina. Retrieved from http://www.casacolumbia.org/absolutenm/articlefiles/379Teen\%20Tipplers.pdf

Hawkins, J. D., Catalano, R. F., \& Miller, J. Y. (1992). Risk and protective factors for alcohol and other drug problems in adolescence and early adulthood: Implications for substance use prevention. Psychological Bulletin, 112, 64-115.

Johnston, L. D., O’Malley, P. M., Bachman, J. G., \& Schulenberg, J. E. (2008). Monitoring the future national results on adolescent drug use: Overview of key findings, 2007 (No. NIH Publication No. 08-6418). Bethesda, MD: National Institute on Drug Abuse.

Latendresse, S., Rose, R., Viken, R., Pulkkinen, L., Kaprio, J., \& Dick, D. (2008). Parenting mechanisms in links between parents' and adolescents' alcohol use behaviors. Alcoholism: Clinical \& Experimental Research, 32, 322-330.

Lintonen, T., Ahlstrom, S., \& Metso, L. (2004). The reliability of self-reported drinking in adolescence. Alcohol and Alcoholism, 39, 362-368.

Lomax, R. G. (1992). Statistical concepts. White Plains, NY: Longman.

Long, J. S., \& Freese, J. (2006). Regression models for categorical dependent variables using STATA (2nd ed.). College Station, TX: STATA Press. 
Luthar, S. S. (2006). Resilience in development: A synthesis of the research across five decades. In D. Cicchetti \& D. J. Cohen (Eds.), Developmental psychopathology: Risk, disorder, and adaptation (2nd ed., Vol. 3, pp. 739-795). New York: Wiley.

Maney, D. W., Higham-Gardill, D. A., \& Mahoney, B. S. (2002). The alcohol-related psychosocial and behavioral risks of a nationally representative sample of adolescents. Journal of School Health, 72, 157-163.

National Center on Addiction and Substance Abuse. (2003, February). Teen tipplers: America's underage drinking epidemic. New York: Author. Retrieved May 30, 2006, from http://www.cpc.unc.edu/projects/addhealth

Pollard, J. A., Hawkins, J. D., \& Arthur, M. W. (1999). Risk and protection: Are both necessary to understand diverse behavioral outcomes in adolescence? Social Work Research, 23, 145-158.

Resnick, M. D., Bearman, P. S., Blum, R. W., Bauman, K. E., Harris, K. M., Jones, J., et al. (1997). Protecting adolescents from harm. Journal of the American Medical Association, 278, 823-832.

Romelsjo, A., \& Branting, M. (2000). Consumption of illegal alcohol among adolescents in Stockholm County. Contemporary Drug Problems, 27, 315-333.

Rutter, M. (1987). Psychosocial resilience and protective mechanisms. American Journal of Orthopsychiatry, 57, 316-331.

Scheier, L. M., Botvin, G. J., \& Baker, E. (1997). Risk and protective factors as predictors of adolescent alcohol involvement and transitions in alcohol use: A prospective analysis. Journal of Studies on Alcohol, 58, 652-667.

Sinha, J. W., Cnaan, R. A., \& Gelles, R. J. (2007). Adolescent risk behaviors and religion: Findings from a national study. Journal of Adolescence, 30, 231-249.

Steinberg, L. (2006). Risk taking in adolescence: What changes and why? Paper presented at the Adolescent Brain Development: Vulnerabilities and Opportunities, New York.

Stice, E., Myers, M. G., \& Brown, S. A. (1998). A longitudinal grouping analysis of adolescent substance use escalation and de-escalation. Psychology of Addictive Behaviors, $12,14-27$.

Urberg, K. A., Degirmencioglu, S. M., \& Pilgram, C. (1997). Close friend and group influence on adolescent cigarette smoking and alcohol use. Developmental Psychology, 33, 834-844.

U. S. Centers for Disease Control and Prevention. (2006). Trends in the prevalence of alcohol use. Atlanta, GA: Author. Retrieved June 9, 2006, from http//:www.cdc.gov/yrbs

van der Vorst, H., Engels, R., Meeus, W., Dekovic, M., \& Vermulst, A. (2006). Parental attachment, parental control and early development of alcohol use: A longitudinal study. Psychology of Addictive Behaviors, 20, 107-116.

Voisin, D. R., Salazar, L. F., Crosby, R., Diclemente, R. J., Yarber, W. L., \& Staples-Horne, M. (2005). Teacher connectedness and health-related outcomes among detained adolescents. Journal of Adolescent Health, 337(5), 17-33.

Volkow, N. D., Wang, G.-J., Begleiter, H., Porjesz, B., Fowler, J. S., Telang, F., et al. (2006). High levels of dopamine $\mathrm{D}_{2}$ receptors in unaffected members of alcoholic families. Archives of General Psychiatry, 63, 999-1008.

Werner, E. E., \& Smith, R. S. (1982). Vulnerable but invincible: A study of resilient children. New York: MacGraw-Hill.

Windle, M., Mun, E. Y., \& Windle, R. C. (2005). Adolescent to young adulthood heavy drinking trajectories and their prospective predictors. Journal of Studies on Alcohol, 66, 313-322. 
Zweig, J. M., Phillips, S. D., \& Lindberg, L. D. (2002). Predicting adolescent profiles of risk: Looking beyond demographics. Journal of Adolescent Health, 31, 343-353.

Karen A. Randolph is an associate professor at the College of Social Work, Florida State University. Her research interests focus on youth at risk, substance use prevention, and family engagement. She is principal investigator on a 3-year project investigating environmental strategies to increase parent engagement in youth substance abuse prevention. Recent publications include "Measuring Alcohol Expectancies in Youth" appearing in Journal of Youth and Adolescence (with M. Gerand \& B. Miller; 2006) and "The Dynamic Nature of Risk Factors for Substance Use Among Adolescents" appearing in Journal of Child \& Adolescent Substance Abuse (2004).

David Russell is an National Institute of Mental Health postdoctoral fellow at the Institute for Health, Health Care Policy, and Aging Research at Rutgers University. His current research focuses on social status differences in stress exposure and mental health across the life course, including an examination of the influence of living alone on depression and loneliness in older adults. A recent publication titled, "The Social Antecedents of Anger in Young Adulthood," coauthored with R. J. Turner, P. Hutto, \& R. Glover appears in the Journal of Health and Social Behavior (2007).

Kathryn Harker Tillman is an assistant professor of sociology and a research associate of the Center for Demography and Population Health at Florida State University. Her research focuses primarily on the educational and behavioral outcomes of American youth. She is currently involved in several projects examining the links between these outcomes and the familial and social contexts in which adolescents live. Recent publications include "Non-Traditional Siblings and the Academic Outcomes of Adolescents" appearing in Social Science Research (2008) and "Who's Doing It? Patterns and Predictors of Youths' Oral Sexual Experiences" appearing in Journal of Adolescent Health (with K. L. Brewster; 2008).

Frank D. Fincham is director of the Florida State University Family Institute. His research focuses on forgiveness, especially in family relationships, and the impact of interparental conflict/divorce on children. He has also contributed to the literature on substance abuse and the family. Recent publications include "Substance-Abusing Parents' Attitudes Toward Allowing Their Custodial Children to Participate in Treatment: A Comparison of Mothers Versus Fathers" appearing in Journal of Family Psychology (with W. Fals-Stewart \& M. L. Kelley; 2004) and "Adolescent Marital Expectations and Romantic Experiences: Associations With Perceptions About Parental Conflict and Adolescent Attachment Security" appearing in Journal of Youth and Adolescence (with S. J. Steinberg \& J. Davila; 2006). 